\title{
The prevalence of risky sexual behaviours amongst undergraduate students in Jigjiga University, Ethiopia
}

\author{
Azwihangwisi Helen Mavhandu-Mudzusi", Teka tesfay Asgedom ${ }^{1}$ \\ Department of Health Studies, University of South Africa, Preller Street, Muckleneuk Ridge, Pretoria, 0003, \\ South Africa
}

\section{A R T I C L E I N F O}

Article history:

Received 19 February 2015

Accepted 2 November 2015

Available online 12 April 2016

Keywords:

Condom use

Risky sex

Sexual behaviour

Sexual partners

Students

\begin{abstract}
A B S T R A C T
Young adults including university students are at high risk of acquiring HIV due to their risky sexual practices. The aim of this study was to determine the prevalence of risky sexual behaviours amongst regular undergraduate students in Jigjiga University. The researcher used a quantitative, univariate cross-sectional descriptive study. Two hundred and thirty six (236) students were selected using a simple random sampling technique. Data were collected using a standardised structured questionnaire. The study revealed that $70.53 \%$ of respondents were sexually experienced. Majority $(54.8 \%)$ of the sexually experienced respondents were sexually active within 3 months of the study. Up to $30.14 \%$ of sexually experienced respondents have had sex with a person other than their current partner in the past 12 months. Only 59.6\% of the sexually experienced respondents used condom in their most recent sexual engagement. The findings of this study showed that university students are involved in sexual behaviours that may increase their risk of contracting HIV infection. Based on the above results, researchers recommended the designing of interventions which are contextually relevant to Jigiga University to mitigate risky sexual practices amongst university students.
\end{abstract}

(C) 2015 The Authors. Publishing services by Elsevier B.V. on behalf of Johannesburg University. This is an open access article under the CC BY-NC-ND license (http:// creativecommons.org/licenses/by-nc-nd/4.0/).

\section{Introduction}

Human Immunodeficiency Virus (HIV) infection has been one of the top health related challenges for the past three decades. This is especially imperative for the African nations which bear $67 \%$ of the world's HIV/AIDS burden (World Health Organisation WHO, 2010). Risky sexual behaviours contribute to the high HIV prevalence in Africa (Cherie \&
Berhane, 2012). Studies indicate that young adults, including college students are at high risk of contracting HIV due to their risky sexual practices (Cherie \& Berhane, 2012). The contributory factor to the high risky sexual behaviour is technological transitions, which make it easier to distribute sexual information from more liberal to more conservative societies (WHO, 2006). Other factors contributing to sexual risky behaviours according to Graham (2012) include peer pressure, unlicensed erotic films, drugs and alcohol abuse. Moreover,

\footnotetext{
* Corresponding author. Tel.: +27 12429 2055; fax: +27 8661884983.

E-mail address: mmudza@unisa.ac.za (A.H. Mavhandu-Mudzusi).

${ }^{1}$ Tel.: +27 12429 2055; fax: +27 8661884983 .
}

Peer review under responsibility of Johannesburg University. 
advances in contraceptives have freed sexual expression from its reproductive consequences (Elizabeth \& Imo, 2008).

Studies have also showed that sexual risky behaviours such as early sexual debut in Ethiopia are still high. About $40.6 \%$ of in-school youths who have had sexual experience started sex before the age of 15 years (Seme \& Wirtu, 2008). According to the Ministry of Health: HIV/AIDS Prevention and Control Office (HAPCO 2005), approximately $61.3 \%$ youth were sexually active within the preceding 12 months of a Behavioural Surveillance Survey round II. From the total number of respondents in the Behavioural Surveillance Survey round II survey, $22.7 \%$ (31.2\% males and $2.7 \%$ females) had more than one sexual partner (HAPCO 2005). Nevertheless, there was slight increase in the median age of sexual debut from 17.3 years in 2000 to 18.5 years in 2005 among females and from 18.7 years to 20.5 years among males (Suzuki et al. 2008).

Sexual behaviour needs to take a central position in the heart of public health policy makers and researchers. This is important in view of its association with Sexually Transmitted Infections (STIs), including HIV. This is more important in the African continent because it comprises $13 \%$ of the world population, and bears $67 \%$ of the world's HIV/AIDS burden (Maticka, 2012). Though the prevalence of HIV/AIDS is declining in Ethiopia (3.5\% in 2005 to 1.5\% in 2011), the country is still one of the hardest hit in the continent of Africa (HAPCO, 2012). The age specific prevalence of HIV in Ethiopia shows that people between the ages 20-29 are the most infected (Central Statistical Agency and International Coach Federation International, 2012). HIV in Africa including Ethiopia is primarily transmitted heterosexually due to risky sexual behaviours such as premarital sex, having concurrent multiple sexual partners, and transactional sex. These behaviours are also prevalent amongst college students. Shefer, Clowes, and Vergnani (2012) also reported that 25\% of Ethiopian students are exposed to at least one sexual risk behaviours.

The high rate of premarital sex and having multiple sexual partners among college students are usually associated with non-condom use (Tilahun, Assefa, \& Belachew, 2010). Although multiple interventions in schools in Ethiopia have been successful in increasing knowledge, attitude and perception (KAP) related to condoms, few have resulted in increased correct and consistent use of condoms (Higgins \& Cooper, 2012). Furthermore, Gulliksen and Audensen (2013) indicated that enrolment in higher education institutions in Ethiopia has increased by $120 \%$ since 2008 . However, studies on sexual behaviour among college students in general in Ethiopia are scanty (HAPCO, 2012; Lewis, Blayney, Lostutter, \& Kilmer, 2012). The objective of this study was to determine the prevalence of risky sexual behaviours amongst undergraduate students at Jigiiga University in Ethiopia.

\section{Research methods and design}

This quantitative univariate cross-sectional descriptive study was conducted to determine the prevalence of risky sexual behaviours amongst undergraduate students at Jigjiga University. Jigjiga University is one of 31 public universities in Ethiopia. For 2010/2011 academic year, the university had enrolled a total of 7480 regular students (Jigjiga University 2010). Simple random sampling method was employed. The sampling frame information was provided by the Jigiga University Registrar's Office upon fulfilling all the ethical requirements. Only students who met inclusion criteria were allowed to participate. The inclusion criterion for this study was being a regular undergraduate student within the age range of $18-25$ years and in the graduating class at Jigjiga University. Students in the summer and/or extension programme of the university as well as those in a regular programme, but not in their graduating class in the 2013/14 academic year were excluded. A total of 236 students were randomly selected by computer using a simple random selection approach. The sample size of this study was determined using the following formulan $=\frac{z_{\alpha 2}^{2}(p(1-p))}{d^{2}}$. Based on assumption of prevalence of in-school youth premarital sex of 9.9\% from the Ethiopian round two Behavioural Surveillance Survey (HAPCO 2005), 95\% level of confidence corresponded toz $z_{\alpha / 2}=1.96$, with statistical power of $90 \%, 4 \%$ margin of error, and $10 \%$ non-response rate gave a sample size of 236 .

Structured questionnaire was used for data collection. The questionnaire was partially developed by the researchers. Some aspects of the questionnaire were adapted from the 2011 Ethiopian Demographic and Health Survey tool and Behavioural surveillance Survey round two. The research questionnaire comprised of two sections. Section A contained questions on demographic characteristics of the participants. Section B contained questions on sexual behaviours of the participants. Questions on sexual behaviours included premarital sex, multiple sexual partners, condom use and sexual activities in association with substance use. The questionnaire was piloted on ten students of similar profile with respondents at another university. Their comments were included in the final version of the questionnaire. The questionnaire was pre-tested and assessed against a set of criteria such as time taken to complete, difficulty in understanding the essence of ideas and the presence of any emotionally burdening questions.

A self-reporting data collection method was used as it is difficult to gather information related to sexuality and sexual behaviours. Two lecturers from the department of health at Jigiga University helped the researchers during data collection. At the time of administering the research questionnaire to each participant, clarification on any difficulties were made. Explanations on words like sex, age of sexual debut and the skip patterns was provided to each respondent. Respondents were provided with a locked box with an opening into which they put all completed questionnaires. This was done to ensure anonymity and also to reduce social desirability bias. For data analysis, the researchers used Statistical Package for Social Science (SPSS, v.16). Descriptive statistical procedures such as tables, graphs and proportions were used to report and describe findings.

\section{Ethical consideration}

Ethical principles of beneficence, respect for human dignity and justice highlighted in Polit and Beck (2008) were implored throughout the study. Ethical clearance and approval of the 
study was issued by the University of South Africa and Jigjiga University. All prospective participants were informed about the expected risks such as possible negative emotions due to sensitivity of some questions, estimated time to complete the questionnaire, the right to decline and the right to withdraw from the study at any time. Consent was obtained from each respondent. For anonymity purposes, verbal consent from respondents was equally accepted as written consent. Locked boxes were made available for participants to drop off their completed questionnaire.

\section{Validity and reliability}

External validity of the study was enhanced by selecting a representative sample using a simple random sampling probability technique. Large sample size was used to reduce random sampling error. A standardized questionnaire with known validity and reliability was adopted from the Ethiopian Behavioural Surveillance Survey 2005 and EDHS 2011 to ensure data validity and reliability. A pre-test of the questionnaire was conducted with a few students of similar profile at another university to check for consistency, accuracy and reliability of the tool and modifications done as deemed appropriate before embarking on final data collection. Besides, $10 \%$ of the data was re-entered and compared with the already entered data. Internal consistency of a questionare was determined using cronbach's alpha, which is 0.6. Equivalence, which is agreement or degrees between two items on a scale or measure was ensured through the use of Cohen's Kappa which was 0.7. Agreement was noted between scores of different items. To ensure internal validity of this study, two lecturers from the department of health and one of the researchers closely monitored data collection process.

\section{Results}

The majority $(94.07 \%$ [ $n=222])$ of the total sample size $(n=236)$ consented and participated in the study. Only $6.37 \%$ $(n=15)$ of questionnaires were excluded from the data analysis as they were incomplete. Therefore, of the total of 222 consented participants, $87.71 \%(n=207)$ of respondents' questionnaires were included in the final data analysis.

\subsection{Biographical information}

Frequency distribution was used to categorise the respondents' age, sex, religious affiliations and marital status. The majority ( $85.5 \%[\mathrm{n}=177]$ ) of respondents were males and $14.5 \%(\mathrm{n}=30)$ females. Gender composition was disproportionate compared to the Behavioural Surveillance Survey round II. Mean and standard deviation of the age of the respondents was 22.76 years and 2.3 years respectively while the median age was 23 years. The majority $(51.30 \%, n=110)$ of respondents had religious affiliation of Orthodox Christians followed by $22.20 \%(n=46)$ Muslim and $18.80 \%(n=39)$ Protestant. Only $2.40 \%(n=5)$ were Roman Catholic followers while $1 \%(n=2)$ mentioned not having any religious affiliation. The majority $(88.70 \%[n=157])$ of male and $86.67 \%$
( $n=26$ ) of female respondents have never been married while only $10.20 \%(n=18)$ of males and $13.33 \%(n=4)$ of females were married. Only $1.10 \%(n=2)$ of males and no female respondents were separated.

\subsection{Sexual behaviours}

Result analysis pertaining to this section was guided by the research question: "What is the prevalence of sexual risky behaviours amongst undergraduate students in Jigjiga University?" The items of the instrument pertaining to sexual behaviour included: premarital sex elicited by questions on sexual experiences, the type of sexual experiences respondents have had; practice of multiple sexual partnership elicited by questions about the number of sexual partners they have.

\subsection{Premarital sex}

The majority $(67.67 \%$ [ $n=122])$ of the respondents who were never married reported that they have had sex, while $32.2 \%$ $(n=59)$ of this group of respondents reported that they never had sex or any sexual experience before.

Respondents were also asked if they have ever practiced oral and/or anal sex. Results indicated that $12.43 \%(n=22)$ of males and $26.6 \%(n=8)$ of female respondents had practiced oral sex. Results further indicated that, $9.6 \%(n=17)$ of males and $13.33 \%(n=4)$ of female respondents who were sexually experienced reported that they had had anal sex.

\subsection{Age of sexual debut}

When asked at what age respondents had their first sexual intercourse, the majority $45.2 \%(n=66)$ of the sexually experienced respondents reported that they started engaging in sex at the age of $20-24$ years. Only $5.5 \%(n=8)$ of the sexually experienced respondents reported that they started sex before the age of 15 years.

Sexual initiation before the age of 15 years was higher for females $(6.67 \%)$, than their male (3.4\%) counterparts. Most (31.64\% of males and $33.33 \%$ of females) sexually active respondents started sex at the age of 20-24 years, which was likely to be when they enrolled in college.

\subsection{Current sexual activity}

The results showed that $54.8 \%(n=80)$ of the sexually experienced respondents had their last sexual intercourse within the past 3 months of this study, while $23.3 \%(n=34)$ had sexual intercourse within the last 4-6 months. Similarly, $12.3 \%(n=18)$ admitted to having sex within the last $7-12$ months and $9.6 \%(n=14)$ stated doing so in the last year or more with their last sexual partners. The first sexual encounter with the respondents' current sexual partner for most $(54.8 \%, \mathrm{n}=80)$ of the sexually experienced respondents was within the past 1 year.

\subsection{Age of respondents' sexual partners}

The majority $43.8 \%(n=64)$ of the sexually experienced respondents did not know their partners' age, but $25.3 \%(n=37)$ 
of them reported that their partners were between the ages of $20-24$ years and $7.5 \%(n=11)$ above the age of 25 years.

\subsection{Multiple sexual partnerships}

Results indicated that $30.14 \%(n=44)$ of the sexually experienced respondents had sex with a person other than their current sexual partner in the past 12 months. About $13.7 \%$ ( $n=20$ ) of the sexually experienced respondents had sex with two different partners, while $4.1 \%(n=6)$ reported having had sex with three different partners, and 2.1\% $(n=3)$ reported doing so with more than three partners in the past 12 months.

\subsection{Condom use}

There are several issues which emerged from the results regarding condom use. Aspects highlighted in results regarding condom use are the following:

\section{- Condom Use with Last Sexual Partner}

When asked if respondents had ever used condom with their last sex partner? About, $59.4 \%(n=87)$ of the sexually experienced respondents of which $82.75 \%(n=72)$ were males and $17.25 \%(n=15)$ females, indicated that they used a condom with their last sexual partner.

Results shows that from the total number of sexually experienced respondents, $34.43 \%(n=42)$ males and $37.50 \%$ $(n=9)$ females indicated never using condoms with their last sexual partners. Similarly, 39.54\% $(n=48)$ of males and $20.83 \%$ $(n=5)$ females of the sexually experienced females stated they always used condoms. About $13.11 \%(n=16)$ of males and $20.83 \%(n=5)$ females stated that they occasionally used condoms. In addition, $44.26 \%(n=54)$ of the sexually active male, and $29.17 \%(n=7)$ female respondents reported that they used condom with their last sexual partner in the past 12 months.

\section{- Reasons for not Using Condoms}

The majority $42.00 \%(n=21)$ of males and $(50.00 \%(n=4)$ of females amongst those respondents who did not use condom during their last sexual intercourse cited "never thinking about it" as a reason for not using condoms. Other reasons for not using the condoms mentioned by respondents were: afraid of telling sexual partner to use condom $(16.00 \%(n=8)$ of males and $12.50 \%(n=1)$ of females), followed by being in a hurry to have sex $(14.00 \%(n=7)$ of males and $(12.50 \%(n=1)$ females were cited as additional reasons for not using condoms.

\subsection{Commercial sex}

About $31.97 \%$ ( $n=39$ ) of the sexually experienced male respondents paid for sex in the past 12 months while their female counterparts did not. The majority $(38.52 \%[n=47)$ of male and $4.17 \%(n=1)$ of female sexually experienced respondents had paid for sex at some point in their life.

\subsection{Transactional sex}

In response to whether respondents had had sex with older persons in exchange for any kinds of benefit, only $12.5 \%$ of female and $13.11 \%$ of male sexually experienced respondents indicated "yes". The majority $(25 \%[n=6])$ of female and $4.92 \%$ $(n=6)$ of male sexually experienced respondents stated that they did not had sexual intercourse in return for any benefits.

\subsection{Substance use}

About $25.20 \%(n=37)$ of the sexually experienced respondents reported that they or their sexual partners used alcohol. Among those who used alcohol, $8.20 \%(n=12)$ stated that they had sex while they were drunk. About 10.90\% $(n=16)$ mentioned they chewed khat during their last sexual encounter. While $8.80 \%(n=13)$ reported that both partners were drunk, $10.90 \%(n=16)$ reported both partners chewed khat.

\section{Discussion}

The findings of this study indicated that $67.67 \%$ of the respondents have had sex before marriage. This prevalence was higher than the figures reported from the Behavioural Surveillance Survey II, which revealed $9.9 \%$ prevalence of premarital sex experiencers (MOH/HAPCO, AAU, Central Statistical Agency \& EPHA, 2005) among school youth. This difference is not surprising as the age of the respondents are not the same. In this study the respondents are older as compared to the school youth. This attest to the study by Diarsvitri, Utomo, Neeman, and Oktavian (2011) who reported that prevalence of sexual experience amongst youth seems to increase with age.

In relation to other sexual practices other than vaginal sex, $12.43 \%$ of males and $26.6 \%$ of female respondents have practiced oral sex. Results further indicated that, $9.6 \%$ of males and $13.33 \%$ females have had anal sex. These figures were higher than that reported by Cherie and Berhane (2012) who documented that $5.4 \%$ of high school students in Addis Ababa practiced oral sex. Although these figures are high, it was nonetheless surprising because university students are sexually experienced than high-school youth.

The high prevalence of non-vaginal sex by females compared to males in this study may be related to fear of pregnancy, or wanting to maintain virginity. Though these practices, especial anal sex may prevent females from conceiving, the risk of HIV infection is highly increased by practicing anal sex.

However, the prevalence on anal sex is less than that reported in Indonesia, where $27 \%$ of the sexually active respondents were reported to have practiced anal sex. The present study prevalence were less than those reported by Higgins, Trussell, Moore, and Davidson (2010:35) which indicated that $32 \%$ of participants between the ages 18 and 24 years in the USA practiced anal sex in 2002.

With regard to age of sexual debut, the majority of sexually experienced respondents started sex at the age of 20-24 years. It was reassuring to find that few respondents reportedly 
initiated sex before the age of 15 years as delaying sexual debut is considered protective behaviour against STIs transmission (Central Statistical Agency \& ICF International, 2012:190). This prevalence was very low as compared to the findings in earlier studies. The Behavioural Surveillance Survey II study reported that $40.6 \%$ of the $9.9 \%$ sexually active inschool youths started sex before the age of 15 years ( $\mathrm{MOH} /$ HAPCO et al., 2005). Delayed sexual debut in current studies might be the indication that sex education regarding the dangers of early sexual debut offered at school is effective. Other explanation may be aspects of social desirability where respondents might have just responded based on what they assume is 'accepted' sexual debut age.

The EDHS also reported that the median age at first sexual intercourse for women between the ages of 20-24 years was 18 (Central Statistical Agency \& ICF International, 2012). Oljira, Berhane, and Worku (2012) also reported that $24 \%$ of in-school adolescents in Eastern Ethiopia started sex at an average age of 15.5 years. In Indonesia, 32\% of students experienced their first sexual intercourse at the age of $13-14$ years and $68 \%$ of them at 15 years (Diarsvitri et al., 2011).

Sexual initiation before the age of 15 years was higher for females $(6.67 \%, \mathrm{n}=2)$ than their male $(3.4 \%, \mathrm{n}=6)$ counterparts. This result was consistent with the report of $\mathrm{MOH}$ (2007), which noted that Ethiopian young girls engage in sexual activities at a very young age. Results indicated that most (31.64\% of males and $33.33 \%$ of females) sexually active respondents started sex at the age of 20-24 years, which was likely to take place when they enrolled in college. This may indicate that college environment or the notion of being in college makes students more susceptible to risky sexual practices, as they are free from parental control. Supporting this idea, Rosiers, Schwartz, Zamboanga, Ham, and Huang (2012) stated that the concentration of same age group peers and the absence of adult supervision in college settings may exacerbate risky sexual behaviours. Sabone et al. (2007) also reported that university students are at the stage of physiological and psycho-social development in which sexual urges and activities are difficult to contain.

The results showed that $54.8 \%$ of the sexually experienced respondents had their last sexual intercourse within the past 3 months of this study. These showed that respondents were particularly sexually active on college campus. The results differed from other surveys that reported that $30 \%$ of Ethiopian women around the ages of 16 were sexually active (Govindasamy, Kidanu \& Bantayerga, 2002). Results of this study concurred with the findings of MOH/HAPCO et al. (2005) mentioning that overall $61.3 \%$ of students were sexually active within the preceding 12 months of the Behavioural Surveillance Survey round II survey. The high prevalence of sexual activities among unmarried youth increases the risk of contracting HIV, especially if they are not using condoms.

There is high prevalence $(54.8 \%)$ of respondents whose sexual encounter with their previous sexual partner was within the past year. This showed that most of the sexually experienced respondents met with their current sexual partner just within the past year. This indicates a high prevalence of changing sexual partners when enrolling in colleges and had sexual partners puts respondents at risk of acquiring STIs, including HIV.
It was encouraging to know that only $7.5 \%$ of the respondents had sexual partners above 25 years of age. In Italy, Trani, Gnisci, Nobile, and Angelillo (2005) reported that young women attract older partners. A qualitative study in South Africa revealed that college students (mostly girls) have sex with older men for money (Shefer et al., 2012). The sexual relation with older people increases the risk of acquiring HIV infection as older people are more likely to have other sexual partners which increase their probability of being infected with HIV (Joubert \& Ehrlich, 2007). In Addition, older men are more likely to dictate the terms of sex, hence may refuse the use of condoms, which put women at a high risk of contracting HIV.

About $30.14 \%$ of participants indicated that they are engaged in multiple concurrent sexual relationships. This figure was however lower in comparison to the findings of similar studies. For instance, a study amongst preparatory students in Gonder-Ethiopia, reported that $40 \%$ of sexually active students had multiple sexual partners (Shiferaw et al., 2011). On the contrary, the Behavioural Surveillance Survey II study reported that only $22.7 \%$ of those who started sex at colleges had more than one sexual partner ( $\mathrm{MOH} / \mathrm{HAPCO}$ et al., 2005). According to Owen, Rhoades, Scott, Stanley, and Fincham (2008), the number of life time sexual partners ranged from 3.6 to 6.4 with United States students who had started vaginal intercourse. Males were reported more (6.4) partners than females (3.6). Only $33.6 \%$ of the sexually experienced respondents still have sex with their last sexual partner. This signifies that the respondents frequently changed sexual partners. Arora, Nagelkerke, and Jha (2012:5) stated that having two or more life time sexual partners was strongly associated with HIV-positivity. WHO (2006) further indicated that the time between first sexual intercourse and living with a steady partner was longer for men (6 years) compared to women (0-2 years). Having concurrent sexual partners in either case seems to strongly contribute to the rapid spread of STIs, but this scenario is higher in men than in women.

The high number of sexual partner among males than females may be related to cultural practices in most areas in Ethiopia where aspect of polygamy is not shunned upon. It is also related with gender issues where males have the freedom to propose sexual relationships as compared to females. The fact that men/students who have more sexual partners are valued high may also be a contributory factor for males to have several sexual partners.

Results indicated that $59.4 \%$ of respondents used condom during their last sexual engagement. This indicated that approximately $40 \%$ of the sexually active respondents did not take measures to prevent themselves from contracting STIs including HIV. However, the results also showed higher prevalence of condom use compared to the results of the Ethiopian Behavioural Surveillance Survey II, where only $43.1 \%$ ( $45.2 \%$ of males and $37.3 \%$ of females) sexual active school youth had used condoms (HAPCO et al., 2005). This is higher than the findings by Meekers, Silva, and Klein (2006) where only one third of the youths in Madagascar reported using condoms.

Higgins and Cooper (2012) stated that only few students used condoms correctly and consistently. Maticka (2012) on 
the other hand, indicates that condom usage with regular partners in South Africa and Tanzania is taboo. It is however, reassuring knowing that the reported prevalence of condom use in this study was more or less the same in both males (59.02\%) and females (62.50\%) as it may mean that there is gender equity regarding condom usage. In contrast, this outcome do consistent with the outcome of a study in Madagascar, which reported the gender gap in condom use practice to be $42 \%$ and $21 \%$ for males and females, respectively (Meekers et al., 2006). The same was reported by Maticka (2012) stating that men use condom more than their women counterparts.

Males reported to use condoms more than females. The key question to ask here was: with whom do the males use the condoms when female usage is widely reported as 'low'? WHO (2006) attributes this difference to the probability of young women's partners being their husbands with whom condoms are less often used. But could it possibly also be that female respondents just seem to under-report their condom usage while male respondents over report condom usage.

In addition, $44.26 \%$ of the sexually active male and $29.17 \%$ female respondents reported that they did not use condom with their last sexual partner in the past 12 months. These results are similar with the findings in a study conducted by Ma et al (2006) in China which indicated that 35\% of the sexually active female students never used condoms. Several reasons for not using condoms were raised ranging from being in a hurry to have sex, never thought about it, and not having condoms. The reasons given concur with the findings of Mavhandu-Mudzusi, Kutame and Netshandama (2011). The results of this study revealed different reasons to the ones reported in a study in Indonesia conducted by Diarsvitri et al. (2011) in which $30 \%$ of male students cited 'not having condoms' and $37 \%$ of females stated "being afraid of asking their partner" as reasons for not using a condom. The findings indicated that almost half of the respondents never thought of using condom in their last sexual encounter. This in turn showed that either the respondents ignored the risk of the encounter, or were unaware of their encounter being a risky sexual act, or were just unable to avoid possible consequences of such sexual risks.

About $38.52 \%$ of male and $4.17 \%$ of female sexually experienced respondents had paid for sex at some point in their life. A similar report from a study conducted by Shiferaw et al. (2011) indicated that $40 \%$ of the sexually experienced preparatory students in Gonder, Ethiopia visited commercial sex workers. However, the age of respondents who paid for sex in this study is higher as compared to the age reported for preparatory students from other studies in Ethiopia. Sexual experiences, possibly including paying for sex increase with age (Diarsvitri et al., 2011). Apart from paying for sex, results further indicated the involvement of both male and female students in transitional sex. Shiferaw et al. (2011) stated that material gifts and other gestures commonly serve as currency for exchange of transactional sex between older men with adequate money to purchase sex and young girls who sell sex. This findings further concurred with Shefer et al. (2012) mentioning that transactional sex between men and women is common on college campuses where young female students have sex with older men for financial or material benefit. Wamoyi, Wight, Plummer, Mshana, and Ross (2010) also alluded to the irrefutable fact that extreme poverty that extends to the lack of food made Tanzanian female students engage in such practices for money just to buy sugarcane to calm their hunger. Contrary to known facts from similar studies around the world that have reported more women been engaged in transactional sex practices, the results in this study could be attributed to perhaps the under representation of female participants or 'expectation error' of the study.

Findings indicate that about $25.20 \%$ of the sexually experienced respondents reported that they or their partners used alcohol while $10.90 \%$ mentioned they chewed khat during their last sexual encounter. This result concurs to that reported from a study conducted in Addis Ababa medical school indicating that $7 \%$ of respondents used khat. According to the Ethiopian Ministry of Health report, cited by Govindasamy et al. (2002), 77\% of drug abusers and traffickers in Ethiopia were youngsters between the ages of 15-25. Snipes and Benotsch (2013) reported that Alcohol mixed Energy drinks (AmED) were associated with unprotected sex in $69 \%$ of their study participants. Malaju and Asale (2013) also concurred that the number of youths in Gamo Gofa, Ethiopia who used alcohol were 3.8 times more likely to initiate sex before the age of 18 , and khat users were 7.2 times more likely to initiate sexual intercourse than their non-khat user counterparts. Use of alcohol and Khat by respondents or their partners put both of them at risk of HIV infection through having sexual intercourse without a condom, or sex with non-regular partner.

\section{Limitations of the study}

Because the study targeted only regular undergraduate students, which was not representative of all university students, the findings therefore should be generalized or extrapolated with caution to other university student groups. Since this was a cross-sectional study based on retrospective memory data collection, the possibility of memory recall bias or selective memory recall may have occurred. These could have negatively impacted on research findings. Female students were under-represented as some of them did not consent to participate in the study and many of those that participated in the study left the questionnaire incomplete. Again, this negatively affected the outcome of the findings.

\subsection{Recommendations}

Recommendations drawn from the results have been formulated for nursing education, practice and research, and follow below.

- The fact that most respondents were between the ages of 18-25 calls for youth focus interventions such as sex education using edutainment such as drama and music in order to attract them to participate.

- The majority of the sexually active respondents seem to have started sex when they commenced their college education. This needs to be addressed through development of intervention strategies such as 'First thing first' 
programmes for orientating of the first college entering students' to make students delay sex.

- A considerable number of respondents reportedly engaged in sexual relation with older people for financial benefit. This calls for health the initiation of programmes to financially or nutritionally support the very poor students.

- Since the study targeted only regular undergraduate students, and was not a truly representative of all groups of university students, this, calls for future studies to consider including other groups of students to better understand the prevalence of risky sexual practices on college campuses in Ethiopia.

\section{Conclusions}

The prevalence of sexual risky behaviours such as premarital sex, early sexual debut, multiple sexual partnerships including commercial sex was high. This suggests that undergraduate students at Jigjiga University were vulnerable to risky sexual behaviours. Prevalence of condom use among those sexually active respondents was low. This suggested that many respondents did not adopt safe sexual practices. A considerable number of respondents engaged in sex with older partners particularly for material and financial benefits. Such sexual practices may increase their risk of contracting STIs, including HIV. The prevalence of substance use during sexual activity was high. This fact exposes respondents to risky sexual behaviours such as unprotected sex as substance abuse affect the thinking capacity regarding use of precautionary measures when engaging into sexual practices. Most of the respondents did not discuss sexual matters with their sexual partners or with their parents. This makes it difficult to negotiate safer sex practices. This was also reflected in their lack of awareness on safe sex practices such as being faithful and condom use. The majority of sexually active respondents seemed to have initiated sex when they entered college. This fact may show that college students are more prone to early sexual initiation due to increased freedom from parental protection and guidance. These findings mean that students at Jigjiga University are engaging in high risky sexual behaviours which may lead some of them to be infected with HIV before they graduate from the university. The findings comparable to most of the studies conducted in Ethiopia and other countries. Recommendations were made for nursing education, practice and research.

\section{Competing interests}

The authors declare that they have no financial or personal relationship(s) which may have inappropriately influenced them in writing this paper.

\section{Authors' contribution}

TTA: conception of study area, conception of design, data collection, data analysis, interpretation and drafting of manuscript; AHM conception of design, data analysis, drafting of manuscript and critical revision for intellectual content.

\section{Acknowledgements}

The authors would like to acknowledge the University of Jigjiga allowing the researcher to conduct the study and all the students who participated in the studies. This article is based on a Masters study conducted by T.T.A supervised by A.H.M.

\section{R E F E R E N C E S}

Arora, P., Nagelkerke, N., \& Jha, P. (2012). A systematic review and meta-analysis of risk factors for sexual transmission of HIV in India. Plos One, 7(8).

Central Statistical Agency (Ethiopia) \& ICF International Calverton Maryland USA. (2012). Ethiopia demographic and health survey. Addis Ababa: Governmental Publication.

Cherie, A., \& Berhane, Y. (2012). Oral and anal sex practices among high school youth in Addis Ababa, Ethiopia. BMC Public Health, 12(5), 1-9.

Diarsvitri, W., Utomo, I., Neeman, T., \& Oktavian, A. (2011). Beyond sexual desire and curiosity: sexuality among senior high school students in Papua and West Papua Provinces (Indonesia) and implications for HIV prevention. An International Journal for Research, Intervention and Care, 13(9), 1047-1060.

Elizabeth, O., \& Imo, B. (2008). Attitude of Nagierian secondary school adolescents toward sexual practices: implication for counselling practices. European Journal of Scientific Research, 22(2), 177-183.

Govindasamy, P., Kidanu, A., \& Bantayerga, H. (2002). Youth reproductive health in Ethiopia. Addis Ababa: ORC Macro \& MizHasab Research Center.

Graham, C. (2012). Condom use in the context of sex research: a commentary. Sexual Health, 9, 103-108.

Gulliksen, A. K., \& Audensen, E. (2013). Report on recognition of higher of in Eritrea and Ethiopia. Oslo: NOKUT.

Higgins, J. A., \& Cooper, A. D. (2012). Dual use of condoms and contraceptives in USA. Sexual Health, 9, 73-80.

Higgins, J., Trussell, J., Moore, N., \& Davidson, K. (2010). Young adult sexual health: current and prior sexual behaviours among non-Hispanic white US college students. Sexual Health, 7, 35-43.

HIV/AIDS Prevention and Control Office. (2012). Country progress report on HIV/AIDS response. Addis Ababa: HAPCO.

Joubert, G., \& Ehrlich, R. (Eds.). (2007). Epidemiology: A research manual for South Africa (2nd ed.). Cape Town: Oxford University Press.

Lewis, M. A., Blayney, J. A., Lostutter, T. W., \& Kilmer, J. R. (2012). Predictors of hooking up sexual behavior and emotional reactions among U.S. college students. Archives of Sexual Behavior, 41, 1219-1229.

Malaju, M., \& Asale, G. (2013). Association of Khat and alcohol use with HIV infection and age at first sexual initiation among youths visiting HIV testing and counseling centers in GamoGofa Zone, South West Ethiopia. BMC International Health and Human Rights, 13, 10.

Maticka, E. (2012). Condoms in sub-Saharan Africa. Sexual health, 9, 59-72.

Mavhandu-Mudzusi, A. H., Netshandama, V. O., \& Kutame, A. P. (2011). Condom use amongst students requesting emergency 
contraceptive pills at tertiary institutions. Journal of Educational Studies, 10(1), 31-46.

Meekers, D., Silva, M., \& Klein, M. (2006). Determinants of condom use among youth in Madagascar. Journal of Biosocial Science, 38 , 365-380.

MOH. (2007). Multisectoral plan of action for universal access to HIV prevention, treatment, care and support in Ethiopia 2007 - 2010. Government Publications.

MOH/HAPCO, AAU, Central Statistical Agency, \& EPHA. (2005). HIV/AIDS behavioral surveillance survey, Ethiopia round 2. Addis Ababa: Government Publication.

Oljira, L., Berhane, Y., \& Worku, A. (2012). Pre-marital sexual debut and its associated factors among in-school adolescents in Eastern Ethiopia. BMC Public Health.

Owen, J., Rhoades, G., Scott, M., Stanley, S., \& Fincham, F. (2008). "Hooking up" among college students: demographic and psychosocial correlates. Archives of Sexual Behavior, 39, 653-663.

Polit, D. F., \& Beck, C. T. (2008). Nursing research: Generating and assessing evidence for nursing practice (8th ed.). Philadelphia: JB Lippincott.

Rosiers, S., Schwartz, S., Zamboanga, B., Ham, L., \& Huang, S. (2012). A cultural and social cognitive model of differences in acculturation orientations, alcohol expectancies, and alcoholrelated risk behaviors among Hispanic college students. Journal of Clinical Psychology, 00(0), 1-22.

Sabone, M., Ntsayagae, E., Brown, M. S., Seboni, N. M., Mogobe, K. D., \& Sebego, M. (2007). Perceptions of undergraduate students not participating in HIV/AIDS prevention activities in Botswana. Journal Compilation, 332-338.

Seme, A., \& Wirtu, D. (2008). Premarital sexual practice among school adolescents in Nekemte Town, East Wollega. Ethiopia Journal of. Health Development, 22(2), 167-173.

Shefer, T., Clowes, L., \& Vergnani, T. (2012). Narratives of transactional sex on a university campus. An International Journal for Research, Intervention and Care, 14(4), 435-447.

Shiferaw, Y., Alemu, A., Girma, A., Getahun, A., Kassa, A., Gashaw, A., et al. (2011). Assessment of knowledge, attitude and risk behaviors towards HIV/AIDS and other sexual transmitted infection among preparatory students of Gondar town, North West Ethiopia. BMC Research.

Snipes, D., \& Benotsch, E. (2013). High-risk cocktails and high-risk sex: examining the relation between alcohol mixed with energy drink consumption, sexual behavior, and drug use in college students. Addictive Behaviours Journal, 38(1), 1418-1423.

Suzuki, F., Chiho, Y., Mishra, V., Govindasamy, P., Hong, R., \& $\mathrm{Gu}, \mathrm{Y}$. (2008). Changes in HIV-related knowledge and behavior in Ethiopia, 2000-2005: Further analysis of the 2000 and 2005 Ethiopia demographic and health surveys. Calverton, Maryland, USA: Macro International Inc.

Tilahun, D., Assefa, T., \& Belachew, T. (2010). Knowledge, attitude and practice of emergency contraceptives among Adama university female students. Ethiopian Journal of Health Sciences, 20(3), 195-202.

Trani, F., Gnisci, F., Nobile, C., \& Angelillo, I. (2005). Adolescents and sexually transmitted infections: knowledge and behaviour in Italy. Journal of Paediatrics and Child Health, 41, 260-264.

Wamoyi, J., Wight, D., Plummer, M., Mshana, G., \& Ross, D. (2010). Transactional sex amongst young people in rural northern Tanzania: ethnography of young women's motivations and negotiation. Reproductive Health.

World Health Organization. (2006). Sexual behaviour in context: A global perspective. Geneva: WHO Publication.

World Health Organization. (2010). Social determinants of sexual and reproductive health: Informing future research and programme implementation. Geneva: WHO Publication.

\section{F U R T H E R R E A D IN G}

Bowling, A. (2009). Research methods in health: Investigating health and health services (3rd ed.). Berkshire: Open University Press.

Kner, W. (2011). Does condom social marketing improve health outcomes and increase usage and equitable access? Reproductive Health Matters, 19(37), 166-173.

United Nations. (2008). The millennium development goals report. New York: UN Publications.

United Nations program on HIV/AIDS and World Health Organization. (2009). AIDS epidemic update. New York: UNAIDS and WHO Publications.

United States Agency for International Development (Sa): AIDS support and technical assistance resources.

WHO, UNAIDS, \& UNICEF. (2011). Global HIV/AIDS response epidemic update and health sector progress towards universal access: Progress report. New York: UN publications. 